\title{
Desarrollo económico local y competitividad territorial en América Latina
}

\author{
Iván Silva Lira
}

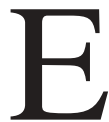

n este artículo se argumenta que en un mundo cada vez más globalizado los gobiernos locales y regionales de América Latina deben asumir nuevos desafíos, entre ellos los de crear o mejorar capacidades competitivas y transformar los sistemas productivos locales. Estos dos aspectos deben vincularse a las políticas territoriales y, más precisamente, al desarrollo de una cultura territorial que integre a ambos. Si bien es cierto que son las empresas las que compiten, su capacidad de competir se puede ver reforzada si el entorno territorial facilita esta dinámica y si, por su parte, ellas también sienten la importancia de ser empresas "del territorio" más que empresas "en el territorio". Esta aspiración, sin embargo, choca con la existencia de territorios desigualmente preparados para enfrentar estos desafíos, lo que aconseja distintos tipos de intervención en términos de políticas públicas locales y regionales tendientes a mejorar sus capacidades competitivas.

Jefe, Área de Desarrollo Local y Regional, Instituto Latinoamericano y del Caribe de Planificación Económica y Social (ILPES), Comisión Económica para América Latina $y$ el Caribe (CEPAL)

$\rightarrow$ ivan.silva@cepal.org 


\section{I}

\section{Introducción}

Actualmente, al formular políticas públicas subnacionales se debiera dar por sentado que la revolución científico-tecnológica ha tenido y seguirá teniendo repercusiones muy significativas sobre los territorios. En particular, las economías nacionales se han hecho más interdependientes; este proceso ha ido acompañado de una reestructuración profunda de los procesos productivos, que se han flexibilizado al surgir nuevas tecnologías para cuya aplicación son indispensables nuevos conocimientos.

La globalización trae consigo muchos cambios de importancia para el futuro de los territorios subnacionales. Desde un punto de vista cultural se observa un doble movimiento: por un lado se tiende a la homogeneización de las identidades culturales, pero por otro se genera cierta resistencia y un retorno a lo local como referente de vida. En otro sentido, y en términos de la variable tiempo, se puede apreciar una aceleración creciente de los procesos y el ritmo de vida y una reducción de las barreras y las distancias entre lugares, debido al desarrollo del transporte y las telecomunicaciones que tiende a hacer más accesibles los territorios desde el punto de vista de los tradicionales factores de atracción territorial.

Todos los cambios que comienzan a verificarse impulsan a crear sociedades cada vez más abiertas y descentralizadas, lo cual redefine el lugar que ocupan y el sentido que tienen los territorios en la aldea global (Boisier, 1996), e implica que estos deben enfrentar nuevos desafíos al formular sus estrategias de desarrollo, en un contexto de mayor complejidad, apertura, competencia, incertidumbre y velocidad de cambio.

En este sentido, se ha llegado a plantear que en la nueva economía global sólo pueden competir los territorios que aprenden, es decir, aquellos capaces de adaptarse a las transformaciones de la estructura productiva mundial, con base en el conocimiento (ampliamente entendido) y su aplicación al sector terciario avanzado, a la industria de alta tecnología y/o a la agricultura comercial. Esto implica que los territorios subnacionales necesitan desarrollar sus respectivas habilidades y ventajas, o su capacidad de construirlas, para especializarse en áreas o sectores que tengan posibilidades de inserción internacional. En la medida en que la globalización provoca la transformación de los territorios subnacionales en espacios de la economía internacional, se refuerza la división territorial y la división social del trabajo. Esta dinámica, además, puede obedecer a distintas lógicas en función de una división horizontal o vertical de los territorios, según sus conexiones con otros lugares del mundo (lógica vertical) o su capacidad de construir redes u organizaciones dentro del mismo territorio (lógica horizontal).

La lógica vertical se podría definir como la lógica de las empresas transnacionales que pueden segmentar sus procesos productivos y distribuir espacialmente la producción, lo que induce a privilegiar criterios de selectividad territorial mediante la valorización de un número limitado de lugares dotados de factores estratégicos para la expansión y competitividad de sus empresas. La lógica horizontal, en cambio, está íntimamente relacionada con la idea de construcción social de los territorios y, más concretamente, con la idea de construir territorios innovadores y competitivos, que hacen de la mesoeconomía territorial una unidad de análisis esencial para propiciar espacios clave de encuentro entre los actores — públicos, sociales y privadoscon miras a modificar el aparato productivo e impulsar un proceso de crecimiento económico con equidad.

En este último sentido, se puede afirmar que la creación de ventajas competitivas tiene un carácter marcadamente local, ya que la estructura económica nacional se puede expresar en torno a cadenas productivas locales que propician el desarrollo de las pequeñas y medianas empresas (sin perjuicio de sus vinculaciones con grandes empresas y de procesos de atracción de inversiones externas) y que tienden a buscar formas asociativas y articuladas para conseguir ventajas competitivas, ya sea bajo el impulso de aglomeraciones productivas (clusters) de empresas organizadas sobre el territorio o de otros tipos de asociaciones productivas, donde el logro de economías de escala se concibe como externo a las empresas pero interno a los territorios. 


\section{II}

\section{Objetivos del desarrollo económico local}

La profunda transformación del régimen económico de la mayoría de los países de América Latina iniciado en la década de 1980 dejó en evidencia que la apertura de los mercados internos, la desregulación y la privatización no han bastado para asegurar la competitividad internacional de las empresas y producir un crecimiento económico alto con una mejoría clara en la distribución del ingreso y en los niveles de vida de la población.

Sobre todo en el plano territorial, es cada vez más importante diseñar instrumentos y políticas públicas de gestión dirigidas a estimular el aprovechamiento de los recursos locales endógenos para impulsar nuevos estilos de desarrollo basados en las potencialidades de las economías locales, como complemento indispensable de las políticas nacionales de desarrollo.

En general, los procesos de desarrollo territorial tienen como objetivos principales la transformación de los sistemas productivos locales, el incremento de la producción, la generación de empleo y la mejora en la calidad de vida de la población. En la búsqueda de estos objetivos, es importante tener en cuenta las modalidades de diseño institucional y los estilos de gestión pública que han adoptado los gobiernos subnacionales de América Latina para propiciar políticas de desarrollo productivo que apunten a la transformación de los sistemas locales de empresas en un clima de mayor competitividad.

En este sentido y con distintas intensidades, particularmente a partir de la década de 1990, se comenzó a incorporar en diversos países de América Latina un enfoque de corte territorial en sus políticas de desarrollo productivo y de fomento a pequeñas empresas, que sería más coherente con los objetivos de crear o mejorar las capacidades competitivas de los sistemas productivos locales. El fomento productivo que se organiza con una perspectiva local/regional ${ }^{1}$ tiene la ventaja, en primer lugar, de estar orientado más cercanamente a la demanda de las empresas, lo que se explica por una mayor proximidad con los "clientes". En segundo lugar, puede ser dirigido hacia sistemas loca-

\footnotetext{
${ }^{1}$ En este artículo, y a menos que se indique otra cosa, el término "regional" se refiere a regiones subnacionales.
}

les de empresas más que hacia empresas individuales, lo que genera evidentes beneficios de aglomeración, permite estimular los procesos de aprendizaje por interacción, y propicia, por lo tanto, la innovación en las actividades económicas.

Sin embargo, para alcanzar estos objetivos se requiere, entre otras cosas, una institucionalidad subnacional descentralizada y un proceso activo de planificación estratégica del desarrollo productivo territorial, que establezca prioridades y canalice hacia objetivos comunes los instrumentos de fomento existentes. La plena operación de un sistema de fomento productivo descentralizado permitiría aprovechar los incrementos de productividad potenciales de los territorios, impactando sobre la tasa agregada de crecimiento nacional en un clima de mayor competitividad.

El reconocimiento de que, para poder desarrollar capacidades competitivas, las pequeñas empresas necesitan asociarse y también contar con apoyos públicos que ayuden a corregir fallas de mercado vinculadas principalmente con la imperfección de los mercados de capital, financiamiento y crédito, la capacitación de recursos humanos y la innovación tecnológica, justifica en gran medida las políticas de fomento que se han diseñado. En este sentido, y como se ha señalado en uno de los buenos trabajos de evaluación que se han realizado sobre las pequeñas empresas en Chile (Bianchi y Parrillo, 2002), los factores que contribuyen al éxito de la pequeña y mediana empresa (pymes) son básicamente tres:

i) La integración en un sistema productivo y social dinámico a nivel local, que permita lograr economías de escala y alcance suficientes para poder competir con grandes empresas en el mercado global.

ii) El mejoramiento de la calidad del producto, del proceso y de los recursos humanos, ya que en los mercados globales no es posible seguir compitiendo por precio (hay actores demasiado poderosos, con economías de escala que les permiten desplazar a cualquier país competidor).

iii) La difusión del conocimiento y las competencias para poder estructurar la economía local de manera de generar bienes con alto valor agregado, de gran calidad e innovadores. El conocimiento 
crea en la empresa una ventaja competitiva que la hace difícil de desplazar.

Por lo tanto, a las razones más tradicionales para apoyar el avance de las pequeñas empresas cabe agregar consideraciones vinculadas con la idea de sistemas locales de empresas, colaboración para competir, asociatividad empresarial, articulación público-privada, generación de conocimiento por interacción y desarrollo de ventajas competitivas, yendo más allá de la noción de que son solamente las empresas las que compiten.

En este sentido, se introduce con fuerza el concepto de territorio como base cultural de sistemas de empresas que desarrollan capacidades competitivas con la colaboración de su entorno, lo que es mucho más que la sola estrategia de fomento aislada de las pequeñas empresas. El esquema que se presenta en el gráfico 1 resume esta proposición. Se plantea que el desarrollo local y regional es un proceso eminentemente endógeno que procura aprovechar sus potencialidades propias -naturales, humanas, institucionales y organizacionales - para transformar los sistemas productivos locales con el propósito de mejorar la calidad de vida de la población.

GRÁFICO 1

\section{Conceptualización de los procesos de desarrollo local y regional}

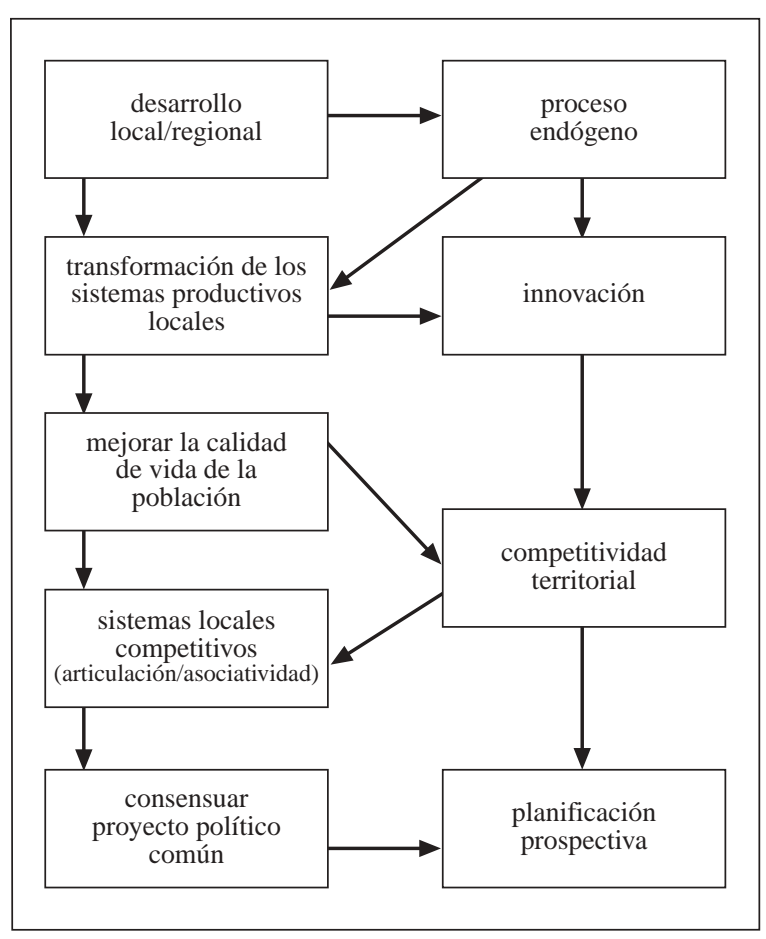

Fuente: Elaborado por el autor.
Es preciso innovar en los sistemas locales de empresas para hacerlos más competitivos, lo que demanda, desde el punto de vista de la organización social, proyectos de desarrollo basados en consensos que interpreten a todos los actores territoriales, para compartir una visión común sobre las áreas estratégicas que habría que impulsar.

Evidentemente, los sistemas productivos locales están constituidos por empresas, y de éstas las de distribución más homogénea sobre los territorios, según la evidencia estadística, son, en este mismo orden, las microempresas y las pequeñas y medianas empresas. En Chile, por ejemplo, las grandes empresas constituyen poco menos del $1 \%$ de las empresas formales del país (4.814 en 1997), y cerca de $73 \%$ de ellas se concentra en la Región Metropolitana. Las microempresas y las empresas pequeñas, en el otro extremo, constituyen el $97 \%$ de las empresas y se distribuyen en forma relativamente homogénea a lo largo del todo el país, en una forma muy similar a la distribución relativa de la población (cuadro 1).

Por lo tanto, cuando se habla de la transformación de los sistemas productivos locales, en la práctica se está hablando de lo que se debe hacer, por ejemplo, para mejorar las capacidades competitivas de una parte de las 3.757 empresas de la región de Aysén en Chile (1.600 km al sur de Santiago), de las cuales 3.256 son microempresas y 486 son empresas pequeñas y medianas (cuadro 1). Esta región tiene un particular perfil productivo y de servicios, y algunas de sus mayores ventajas están asociadas a la acuicultura y el turismo, de modo que en ella toda política que se proponga para la modernización del sistema empresarial debiera tener en cuenta fuertemente la trama productiva local. Esto, sin muchas dudas, difícilmente puede ser abordado sólo con una visión nacional desde el centro del país.

Además, desde un punto de vista más estratégico y de asignación eficiente de los recursos, tampoco se puede pensar que deberá atenderse a todas las empresas de la región. Muchas de ellas inevitablemente desaparecerán, ${ }^{2}$ conforme a la dinámica propia de los

\footnotetext{
2 Véase Cabrera, de la Cuadra y otros (2002). En este texto se senala que las altas tasas de fracaso de las pymes, categoría de empresas que tiene menos éxito que las empresas grandes, no hace sino confirmar el patrón de comportamiento de la dinámica de nacimiento, evolución y salida de empresas en una serie de países de todo tipo. Esta tendencia se debe más al funcionamiento habitual de la economía que a los períodos de recesión por los que ella pueda atravesar. Por lo demás, se afirma que estos procesos favorecen el dinamismo económico agregado, ya que gran parte del crecimiento de la productividad se debe al reemplazo de plantas y
} 


\begin{tabular}{|c|c|c|c|c|c|c|}
\hline \multicolumn{2}{|c|}{ Región } & \multirow{2}{*}{$\begin{array}{l}\text { Micro } \\
14776 \\
87,5 \%\end{array}$} & \multirow{2}{*}{$\begin{array}{c}\text { Pequeña } \\
1834 \\
10,9 \%\end{array}$} & \multirow{2}{*}{$\begin{array}{c}\text { Mediana } \\
213 \\
1,3 \%\end{array}$} & \multirow{2}{*}{$\begin{array}{c}\text { Grande } \\
67 \\
0,4 \%\end{array}$} & \multirow{2}{*}{$\begin{array}{c}\text { Total } \\
16890 \\
100,0 \%\end{array}$} \\
\hline I & Tarapacá & & & & & \\
\hline II & Antofagasta & $\begin{array}{l}12650 \\
82,6 \%\end{array}$ & $\begin{array}{l}2291 \\
15,0 \%\end{array}$ & $\begin{array}{c}273 \\
1,8 \%\end{array}$ & $\begin{array}{c}103 \\
0,7 \%\end{array}$ & $\begin{array}{l}15317 \\
100,0 \%\end{array}$ \\
\hline III & Atacama & $\begin{array}{l}7619 \\
85,6 \%\end{array}$ & $\begin{array}{c}1142 \\
12,8 \%\end{array}$ & $\begin{array}{c}108 \\
1,2 \%\end{array}$ & $\begin{array}{c}33 \\
0,4 \%\end{array}$ & $\begin{array}{c}8902 \\
100,0 \%\end{array}$ \\
\hline IV & Coquimbo & $\begin{array}{l}17647 \\
86,8 \%\end{array}$ & $\begin{array}{l}2373 \\
11,7 \%\end{array}$ & $\begin{array}{c}236 \\
1,2 \%\end{array}$ & $\begin{array}{c}70 \\
0,3 \%\end{array}$ & $\begin{array}{l}20326 \\
100,0 \%\end{array}$ \\
\hline V & Valparaíso & $\begin{array}{l}4528 \\
83,9 \%\end{array}$ & $\begin{array}{c}7343 \\
14,1 \%\end{array}$ & $\begin{array}{c}793 \\
1,5 \%\end{array}$ & $\begin{array}{c}245 \\
0,5 \%\end{array}$ & $\begin{array}{l}51909 \\
100,0 \%\end{array}$ \\
\hline VI & O'Higgins & $\begin{array}{l}23864 \\
85,6 \%\end{array}$ & $\begin{array}{c}3582 \\
12,8 \%\end{array}$ & $\begin{array}{c}346 \\
1,2 \%\end{array}$ & $\begin{array}{c}91 \\
0,3 \%\end{array}$ & $\begin{array}{c}27883 \\
100,0 \%\end{array}$ \\
\hline VII & Maule & $\begin{array}{l}35250 \\
88,7 \%\end{array}$ & $\begin{array}{c}3996 \\
10,1 \%\end{array}$ & $\begin{array}{c}376 \\
0,9 \%\end{array}$ & $\begin{array}{c}116 \\
0,3 \%\end{array}$ & $\begin{array}{l}39738 \\
100,0 \%\end{array}$ \\
\hline VIII & Bío-Bío & $\begin{array}{l}48672 \\
85,2 \%\end{array}$ & $\begin{array}{c}7394 \\
12,9 \%\end{array}$ & $\begin{array}{c}811 \\
1,4 \%\end{array}$ & $\begin{array}{c}254 \\
0,4 \%\end{array}$ & $\begin{array}{l}57131 \\
100,0 \%\end{array}$ \\
\hline IX & Araucanía & $\begin{array}{l}24723 \\
86,2 \%\end{array}$ & $\begin{array}{c}3545 \\
12,4 \%\end{array}$ & $\begin{array}{c}333 \\
1,2 \%\end{array}$ & $\begin{array}{c}90 \\
0,3 \%\end{array}$ & $\begin{array}{l}28691 \\
100,0 \%\end{array}$ \\
\hline$X$ & Los Lagos & $\begin{array}{l}31447 \\
84,6 \%\end{array}$ & $\begin{array}{l}5095 \\
13,7 \%\end{array}$ & $\begin{array}{c}450 \\
1,2 \%\end{array}$ & $\begin{array}{c}197 \\
0,5 \%\end{array}$ & $\begin{array}{l}37189 \\
100,0 \%\end{array}$ \\
\hline XI & Aysén & $\begin{array}{c}3256 \\
86,7 \%\end{array}$ & $\begin{array}{c}439 \\
11,7 \%\end{array}$ & $\begin{array}{c}47 \\
1,3 \%\end{array}$ & $\begin{array}{c}15 \\
0,4 \%\end{array}$ & $\begin{array}{c}3757 \\
100,0 \%\end{array}$ \\
\hline XII & Magallanes & $\begin{array}{l}5014 \\
80,8 \%\end{array}$ & $\begin{array}{c}1032 \\
16,6 \%\end{array}$ & $\begin{array}{c}130 \\
2,1 \%\end{array}$ & $\begin{array}{c}28 \\
0,5 \%\end{array}$ & $\begin{array}{c}6204 \\
100,0 \%\end{array}$ \\
\hline Metro & politana & $\begin{array}{c}150001 \\
75,5 \%\end{array}$ & $\begin{array}{l}38464 \\
19,4 \%\end{array}$ & $\begin{array}{l}6734 \\
3,4 \%\end{array}$ & $\begin{array}{l}3500 \\
1,8 \%\end{array}$ & $\begin{array}{l}198699 \\
100,0 \%\end{array}$ \\
\hline Sin ir & formación & 13984 & 275 & 20 & 5 & 14284 \\
\hline Total & & $\begin{array}{c}432442 \\
82,1 \%\end{array}$ & $\begin{array}{c}78807 \\
15,0 \%\end{array}$ & $\begin{array}{c}10870 \\
2,1 \%\end{array}$ & $\begin{array}{l}4814 \\
0,9 \%\end{array}$ & $\begin{array}{c}526933 \\
100,0 \%\end{array}$ \\
\hline
\end{tabular}

Fuente: Corporación de Fomento de la Producción (CORFO), sobre la base de información del Servicio de Impuestos Internos (SII).

mercados, aunque igualmente es necesario definir una estrategia de intervención que apueste a aquellos sistemas de empresas con mayores posibilidades de éxi-

empresas más ineficientes por otras más eficientes. Por lo tanto, y he aquí la conclusión más impactante, las políticas de apoyo a las microempresas y las pequeñas y medianas empresas (mipymes) que están en problemas sólo retardarán la salida de un gran número de firmas relativamente menos productivas, desperdiciarán recursos públicos que tienen usos alternativos urgentes y obstaculizarán el crecimiento de la productividad, el empleo, los salarios y la economía. En otras palabras, según esta visión, las políticas estatales de to. De ahí, por lo tanto, la necesidad de llegar a una visión público-social-privada compartida sobre las características de tal intervención.

fomento productivo para las mipymes no harían sino obstaculizar la buena marcha de la economía, dilapidarían recursos, retardarían la salida de empresas que de todas maneras van a fracasar; como lógica consecuencia, sería mejor dejar que el mercado resolviera automáticamente estos problemas de asignación. Sin compartir esa visión, la lección que sí se puede desprender de este planteamiento es la necesidad de que los instrumentos de fomento se asignen a empresas cuya viabilidad técnica y económica futura haya sido evaluada. 
Algo similar ocurre en la región de Atacama (800 $\mathrm{km}$ al norte de Santiago), que tiene más empresas que la región de Aysén, pero exhibe una proporción mucho mayor de microempresas $(86,8 \%)$, tiene un perfil productivo muy diferente y, por lo tanto, su diseño de políticas de desarrollo productivo debiera basarse en otro tipo de consideraciones. La cultura del territorio significa, entre otras cosas, historias distintas, habilidades diferentes, formas de hacer las cosas que son propias de cada lugar y están vinculadas con entornos naturales específicos a cada geografía, aspectos todos que influyen en las formas de organización económica y social y que deben ser tomados en cuenta a la hora de diseñar estrategias de intervención. Es ahí donde cobra su mayor validez el enfoque local de las políticas de desarrollo productivo en general, y de aquellas de fomento en particular.

Es natural pensar entonces que las políticas de desarrollo productivo deben tener, al menos en lo que a sistemas locales de empresas se refiere, una marcada aproximación territorial. Así lo han comprendido muchos gobiernos que han comenzado paulatinamente a incorporar esta visión en sus estrategias, aunque con grados muy disímiles de profundidad y con éxitos todavía muy relativos, pero que no se pueden desconocer.

\section{III}

\section{Desarrollo local en un mundo globalizado: hacia la construcción de territorios competitivos e innovadores}

La construcción de capacidades competitivas puede vincularse de hecho a las políticas territoriales y, más precisamente, al desarrollo de una cultura territorial que integre los sistemas locales de empresas y que ayude a superar la situación de mayor deterioro de los territorios más atrasados. Es decir, si bien es cierto que son las empresas las que compiten, su capacidad de competir se puede ver reforzada si el entorno territorial facilita esta dinámica y si, por su parte, las empresas sienten la importancia de ser empresas "del territorio", a cuyos habitantes también se deben, más que empresas que están "en el territorio", desvinculadas totalmente de sus proyectos de futuro y desarrollo.

En particular, es importante comprender que, desde lo local, la gestión pública puede inducir el desarrollo de redes de empresas organizadas con asiento en un particular territorio (clusters), donde la colaboración y la asociatividad de las empresas son elementos centrales para impulsar su competitividad.

La palabra inglesa clusters se refiere a una concentración geográfica de empresas e instituciones, en la cual la interacción genera y sustenta ventajas competitivas. Hasta ahora no existe consenso sobre el equivalente en español del término. Se utiliza "agrupamientos industriales", "distritos industriales" y "agrupaciones locales", en ocasiones con significados leve- mente diferentes. Siguiendo prácticas de la CEPAL, aquí utilizaremos la expresión "aglomeraciones productivas". La idea principal es que por medio del desarrollo de tales aglomeraciones sería posible generar ventajas competitivas avanzadas (principalmente en materia de conocimiento e innovación), de particular relevancia para los grupos de pymes concentradas en un territorio

En otras palabras, hay pruebas convincentes de que mediante la acción colectiva organizada, en general, y la gubernamental, en particular, se podrían encontrar importantes fuentes de competitividad. Porter (1991) ha señalado que la fortaleza y durabilidad de la capacidad de competir de las aglomeraciones productivas radica en su generación de conocimiento especializado y su capacidad de innovación. Estas fuentes "superiores" de competitividad surgen de la interacción entre empresas que son a la vez capaces de competir y de colaborar. En su particular modelo, la acción gubernamental es exógena: es decir, puede incidir (para bien o para mal) en la competitividad, pero no puede explicarla. La acción gubernamental ocupa en esa visión un papel similar al de la causalidad. Esta aproximación, sin embargo, es insatisfactoria para quienes conciben y llevan a cabo acciones colectivas y políticas públicas, particularmente, cuando hoy en día se 
rescata la necesidad de impulsar la articulación público-privada para potenciar el desarrollo de las organizaciones de empresas señaladas (Buitelaar, 2001a y 2001b).

Como ya se ha hecho bastante explícito, por lo tanto, un factor fundamental de competitividad, particularmente en esta nueva sociedad de la información y el conocimiento, es la capacidad de aprendizaje e innovación, que según se estima está latente en instituciones y organizaciones locales y que con cierta habilidad se puede y debe explotar. De aquí que la construcción del concepto de competitividad territorial debiera ser una de las líneas fundamentales de acción de los gobiernos subnacionales.

El gráfico 2 integra los conceptos de aglomeraciones productivas y desarrollo local. La idea que se intenta transmitir es que en la vecindad de un territorio puede convivir una cantidad de empresas que, si se organizan, tienen la posibilidad de desarrollar la capacidad de asociarse, competir, cooperar, eslabonarse, aprender, especializarse, para, en lo posible, explotar toda la cadena de valor de un determinado proceso productivo. Para fortalecerse, estas redes empresariales necesitan, en el ámbito local y regional, la activación de dos variantes de la competitividad, que cobran mayor sentido y toda su dimensión particularmente en el plano territorial, y que son los niveles mesoeconómico y microeconómico de la competitividad sistémica. ${ }^{3}$ Como se expresa en el gráfico 2 , en el nivel microeconómico se trata de introducir los cambios tecnológicos factibles y necesarios para repotenciar el aparato productivo local, para lo cual se puede recurrir a distintos medios. En tanto, en el nivel de la mesoeconomía territorial se trata de impulsar un entorno innovador para el fomento empresarial, lo que implica desarrollar toda una institucionalidad local que efectivamente pueda acometer este desafío.

\footnotetext{
${ }^{3}$ En este contexto, las palabras mesoeconomía y microeconomía provienen del concepto de competitividad sistémica que apunta a capturar los determinantes económicos y políticos del desarrollo industrial exitoso y cuyos ingredientes clave, según Altenburg, Hillebrand y Meyer-Stamer (1988), son: “-al nivel meta: primero, valores de desarrollo culturamente orientados que son compartidos por la mayoría de la sociedad; segundo, un consenso básico de la necesidad del desarrollo industrial y de la integración competitiva al mercado mundial y, tercero, la habilidad de los actores sociales de formular conjuntamente visiones y estrategias y de implementar políticas; - al nivel macro, un marco macroeconómico estable y predecible; esto debe incluir una política cambiaria realista y una política general de comercio exterior que estimule la industria nacional; - al nivel meso: instituciones y políticas específicas para desarrollar industrias y su medio (tecnología, institutos, centros de capacitación, financiamiento de
}

GRÁFICO 2

\section{Aglomeraciones productivas y desarrollo} local

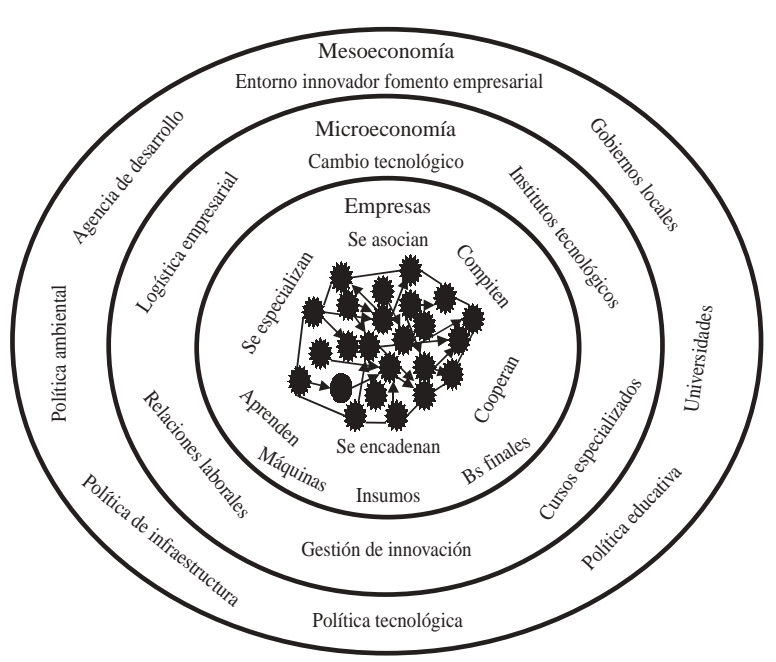

Fuente: Elaborado por el autor.

Para que esto sea factible, sin embargo, y se pueda avanzar realmente hacia la implementación de iniciativas de desarrollo local exitosas, es preciso que los gobiernos subnacionales desempeñen un nuevo rol, particularmente en los planos de la mesoeconomía y microeconomía territoriales y de la articulación público-privada, que pueda contribuir a hacer competitivas a las empresas integrantes de los sistemas locales, con todas las demandas y consecuencias que esto conlleva en los planos social, cultural, político y educativo. Estas nuevas funciones de los gobiernos subnacionales, que se agregan a sus tradicionales tareas, básicamente son:

- Un rol de creador de un entorno favorable para el desarrollo local.

exportaciones, etc.) y crear una ventaja competitiva. Más aún, es el mundo de las iniciativas de competitividad industrial locales y regionales el que debe fortalecer el medio ambiente de las firmas. Muchas de las instituciones que actúan al nivel meso son, o en principio pueden ser, entidades no gubernamentales, como asociaciones de empresarios o entidades sin fines de lucro; - al nivel micro: mejoramiento continuo de las empresas y de las redes de empresas con fuertes externalidades". Como una forma de resumir el concepto de competitividad sistémica puede decirse que el nivel meta se refiere a la capacidad de animación social y concertación estratégica de los actores; el nivel macro está vinculado a la capacidad de asegurar condiciones para reproducir el régimen de acumulación; el nivel meso responde por la creación de un entorno innovador para el fomento empresarial, y el nivel micro tiene que ver con garantizar el cambio tecnológico en el tejido productivo y empresarial existente. 
- Un rol de liderazgo, capaz de activar y canalizar las fuerzas sociales en pos de un proyecto de desarrollo común.

- Un rol articulador público-privado y de impulso a la capacidad asociativa.

- Un rol de fomento productivo y de impulso al desarrollo de los planos mesoeconómico y microeconómico de la competitividad sistémica.

En definitiva, para construir territorios competitivos e innovadores es preciso aprovechar sus recursos endógenos, propiciando la asociatividad y la articula- ción público-social-privada con miras a flexibilizar los procesos productivos. Tales dinámicas están aún escasamente presentes en la lógica de los gobiernos subnacionales latinoamericanos. Los planos mesoeconómico y microeconómico adquieren mayor sentido en el ámbito territorial y de ahí que, en la medida en que ellos no se fortalezcan, sus posibilidades de éxito resultan disminuidas. La idea de que los territorios son los que compiten cobra cada vez más sentido, aun cuando ellos están desigualmente preparados para enfrentar esta tarea, como se verá en la sección siguiente.

\section{IV}

\section{Crecimiento, convergencia y disparidades territoriales}

Un primer factor que debe tenerse en cuenta en términos de las diferentes capacidades que presentan los territorios, es el de los análisis de convergencia territorial que ponen en su contexto una vieja preocupación de los estudiosos de los temas regionales relativa a las desigualdades territoriales y a su comportamiento a través del tiempo. Esta preocupación está estrechamente relacionada con las diversas teorías sobre el crecimiento económico que en su versión neoclásica postulaban la existencia de mecanismos automáticos que llevarían a la convergencia, en oposición a aquellas teorías que señalaban la necesidad de una intervención decidida para corregir dichas disparidades, estrechamente asociada a la investigación de los factores que permitirían dinamizar el crecimiento de las regiones más pobres de un determinado país. ${ }^{4}$

Uno de los autores que han revivido fuertemente este debate a partir de la década de 1990 ha sido Salai-Martin, que en uno de sus trabajos respecto a los conceptos de convergencia señala: "A mediados de los ochenta, los nuevos teóricos del crecimiento endógeno ${ }^{5}$

\footnotetext{
${ }^{4}$ Véase un examen detallado de este tema y de su aplicación a distintos países y regiones en Mancha Navarro y Sotelsek Salem (2001).

${ }^{5}$ El término crecimiento endógeno aquí hace alusión a la incorporación del progreso técnico como un proceso endógeno del modelo asociado a los gastos en investigación y desarrollo (I+D), a diferencia de los postulados anteriores del modelo neoclásico de Solow, cuya característica principal era considerar el progreso técnico como un factor exógeno, con una función de producción caracterizada
}

argumentaron que el supuesto de rendimientos decrecientes del capital llevaba al modelo neoclásico a predecir la convergencia entre naciones. Por el contrario, los rendimientos constantes del capital subyacentes en todos los modelos de crecimiento endógeno comportan la predicción de la no convergencia. El estudio empírico de la hipótesis de convergencia se presentaba, pues, como una manera sencilla de decir cuál de los dos paradigmas representaba una mejor descripción de la realidad" (Sala-i-Martin, 2000). Más adelante en la misma obra argumenta que, sin embargo, "a principios de los años noventa, los economistas neoclásicos hicieron su propia contrarrevolución. Sala-i-Martin (1990), Barro y Sala-i-Martin (1991, 1992a y 1992b) y Mankiw, Romer y Weil (1992) negaron el hecho de que el modelo neoclásico hiciera la predicción de convergencia y negaron, por tanto, que la evidencia presentada hasta entonces pudiera ser utilizada en contra del modelo neoclásico".

Más allá del interesante debate teórico y de las continuas evidencias empíricas que se han generado, lo que se presenta en esta sección son dos de las definiciones de convergencia utilizadas y que, en este caso, tienen por propósito indagar cuál ha sido la evolución de sus territorios en algunos países latinoamericanos. Uno de los conceptos es el llamado de convergencia

por factores de producción sustituibles, rendimientos constantes a escala y rendimientos decrecientes de los factores de producción variables. 


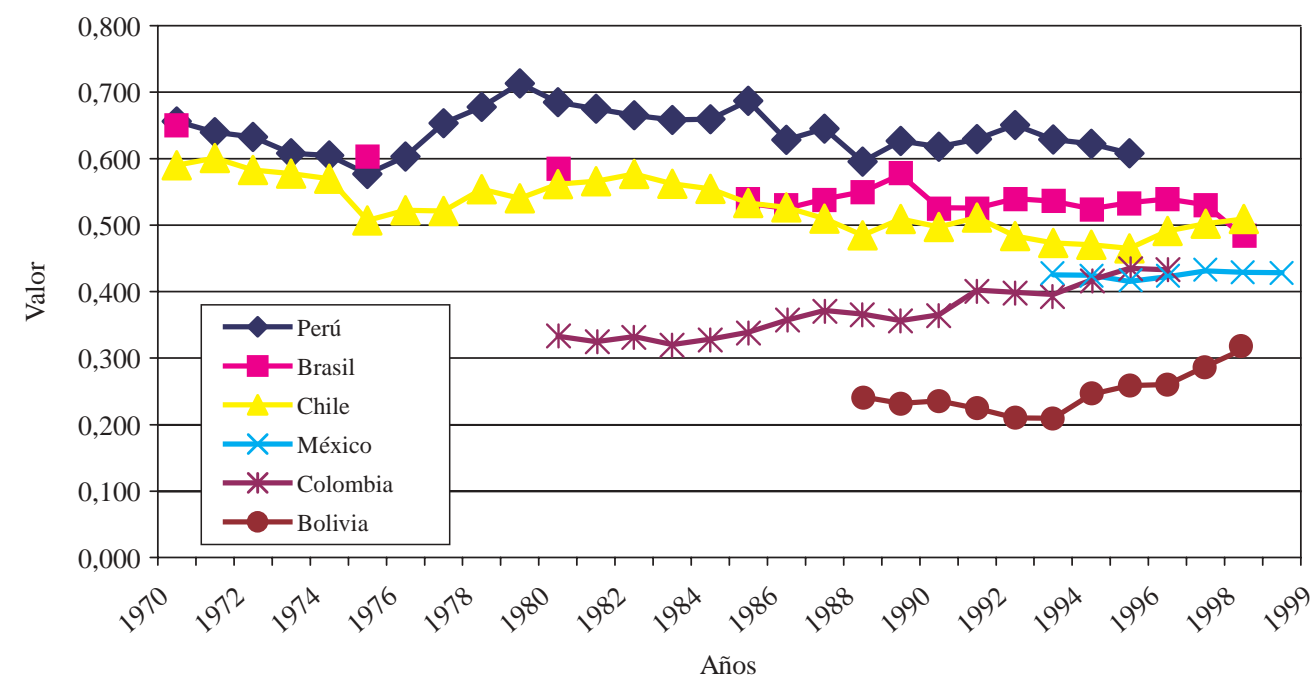

Fuente: Elaborado por el autor.

beta, que afirma que hay convergencia si las economías pobres crecen más que las ricas. El otro es el de convergencia sigma, según el cual hay convergencia si la dispersión del ingreso real per cápita entre grupos de economías tiende a reducirse en el tiempo. ${ }^{6}$

Es esto lo que se presenta a continuación, solamente para aquellos países sobre los cuales se ha podido obtener información económica desagregada por territorios subnacionales intermedios: Bolivia, Brasil, Chile, Colombia, México y Perú. ${ }^{7}$

Ante todo, pasaremos revista a lo sucedido en términos de convergencia territorial, es decir, si el crecimiento de los territorios intermedios ha sido convergente, neutro o divergente en los períodos analizados. Interesa averiguar si los territorios intermedios más pobres están creciendo o no a tasas mayores que los más ricos y comprobar de este modo si hay mayor equidad en su crecimiento a escala nacional. Esta verificación, como ya se comentaba, se hace en términos de la convergencia sigma (S) y de la convergencia beta (B). En ambas situaciones se utiliza el producto interno bruto per cápita; mientras el primer método señala que hay convergencia en la medida en que la dispersión del PIB real per cápita se reduce en el tiempo, es decir, que las

\footnotetext{
${ }^{6}$ El primero en utilizar estas definiciones fue Sala-i-Martin (1990).

${ }^{7}$ Los territorios subnacionales intermedios corresponden a los departamentos en Bolivia, Colombia y Perú; a los estados en Brasil y México y a las regiones en Chile.
}

disparidades entre territorios intermedios tienden a disminuir, el segundo se refiere a la velocidad de la convergencia, esto es, al tiempo que demorarían los territorios intermedios más pobres en alcanzar a los más ricos. En este último caso, por lo tanto, existe convergencia beta entre los territorios intermedios si se encuentra una relación inversa entre la tasa de crecimiento del PIB per cápita y el nivel inicial del PIB, en otras palabras, si los territorios relativamente más pobres tienden a crecer más rápido que aquellos más ricos.

El gráfico 3 presenta los resultados de la convergencia sigma para varios países. Cuando el indicador es cercano a 1 las disparidades son muy acentuadas y cuando es cercano a 0 hay un mayor grado de igualdad territorial. Las series de tiempo son distintas, ya que como se puede observar para Perú, Brasil y Chile, se han obtenido series largas, mientras que para México la serie es muy corta, ya que abarca tan sólo de 1993 a 1999; en el caso de Colombia va de 1980 a 1996, y en el de Bolivia de 1988 a 1998. Es decir, a la dificultad de obtener información desagregada por territorios intermedios se agrega el inconveniente de que las series no son uniformes para todos los países y que algunas no son todo lo actualizadas que se quisiera.

Como muestra el gráfico, las mayores disparidades entre territorios subnacionales intermedios se presentan en Perú, seguido de Brasil, Chile, México, Colombia y Bolivia, en este orden. Además de presentar los grados de desigualdad más bajos entre tales 
CUADRO 2

América Latina (seis países): Análisis de convergencia y divergencia subnacionales (beta)

\begin{tabular}{|c|c|c|c|}
\hline Período & $\begin{array}{l}\text { Tiempo para reducir } \\
\text { la brecha a la mitad }\end{array}$ & Período & $\begin{array}{l}\text { Tiempo para reducir } \\
\text { la brecha a la mitad }\end{array}$ \\
\hline Perú & & México & \\
\hline $\begin{array}{l}1970-1980 \\
1980-1990 \\
1990-1995 \\
1970-1995\end{array}$ & $\begin{array}{l}\text { No convergen } \\
51 \text { años } \\
\text { No convergen } \\
\text { No convergen }\end{array}$ & 1993-1999 & No convergen \\
\hline Brasil & & Colombia & \\
\hline $\begin{array}{l}1970-1980 \\
1980-1990 \\
1990-1997 \\
1970-1997\end{array}$ & $\begin{array}{l}35 \text { años } \\
48 \text { años } \\
\text { No convergen } \\
54 \text { años }\end{array}$ & $\begin{array}{l}1980-1996 \\
1990-1996\end{array}$ & $\begin{array}{l}\text { No convergen } \\
\text { No convergen }\end{array}$ \\
\hline Chile & & Bolivia & \\
\hline $\begin{array}{l}1970-1980 \\
1980-1990 \\
1990-1998 \\
1960-1998\end{array}$ & $\begin{array}{l}\text { No convergen } \\
53 \text { años } \\
\text { No convergen } \\
61 \text { años }\end{array}$ & $\begin{array}{l}1990-1998 \\
1988-1998\end{array}$ & $\begin{array}{l}\text { No convergen } \\
\text { No convergen }\end{array}$ \\
\hline
\end{tabular}

Fuente: Elaborado por el autor.

territorios, Bolivia es el país de menor desarrollo relativo entre los analizados, lo que podría sugerir que esta condición va de la mano con desarrollos territoriales bajos en todos sus departamentos; en todo caso, a partir de 1994 se observa en este país una tendencia creciente al aumento de las disparidades territoriales.

En Perú, entre 1970 y 1995 el indicador se mueve, con fluctuaciones entre 0,60 y 0,70, observándose una pequeña disminución de las disparidades (mayor convergencia) entre 1970 y 1976, año a partir del cual ellas aumentan, para después entrar en una tendencia descendente hasta 1989 y comenzar de nuevo a aumentar lentamente. Los períodos de mayor convergencia en el caso peruano parecen coincidir con épocas de crisis económicas muy acentuadas a nivel nacional, como las de 1982-1983 y 1988-1989; es decir, se trata de convergencia asociada a un deficiente desempeño económico en esos períodos.

En el caso de Brasil los valores se mueven entre 0,50 y 0,60 en el período 1970-1997, y también exhiben fluctuaciones que no señalan una tendencia clara al aumento o disminución de las disparidades. En Chile se observa una muy leve reducción de las disparidades a partir de 1983, año que paradójicamente también coincide con una gran crisis económica en el país, tendencia que se revierte a partir de 1996. Para México, la serie es muy corta y muestra una situación prácticamente constante en términos de desigualdades territoriales entre 1993 y 1999, mientras que para Colombia se aprecia un continuo incremento de las disparidades territoriales entre 1980 y 1996.

En resumen, del gráfico 3 se desprende que las disparidades territoriales en los países analizados tienden a mantenerse o a aumentar levemente en el tiempo, y que cuando ellas disminuyen su reducción tiende a coincidir con períodos de crisis económicas; esto sugiere que la causa está más en la caída brusca del crecimiento de los territorios más ricos que en políticas explícitas para incentivar el crecimiento de los más atrasados.

La información contenida en el gráfico 3 se puede relacionar con la del cuadro 2, que presenta los resultados de la convergencia beta, la misma que indica la velocidad de convergencia. ${ }^{8}$

En general, las velocidades de convergencia obtenidas son extraordinariamente bajas. En el caso de Chile, en el período largo, entre 1960 y 1998, los resultados del modelo señalan que tomaría 61 años reducir a la mitad la brecha de PIB per cápita entre regiones, mientras que si el modelo se aplica al período 1990-1998, uno de los de mayor crecimiento económico en la historia del país y en el que se podría considerar que operaban plenamente las fuerzas de la

\footnotetext{
${ }^{8}$ Véase en el apéndice un cuadro que presenta más detalles sobre los resultados de la regresión no lineal para los distintos países analizados.
} 


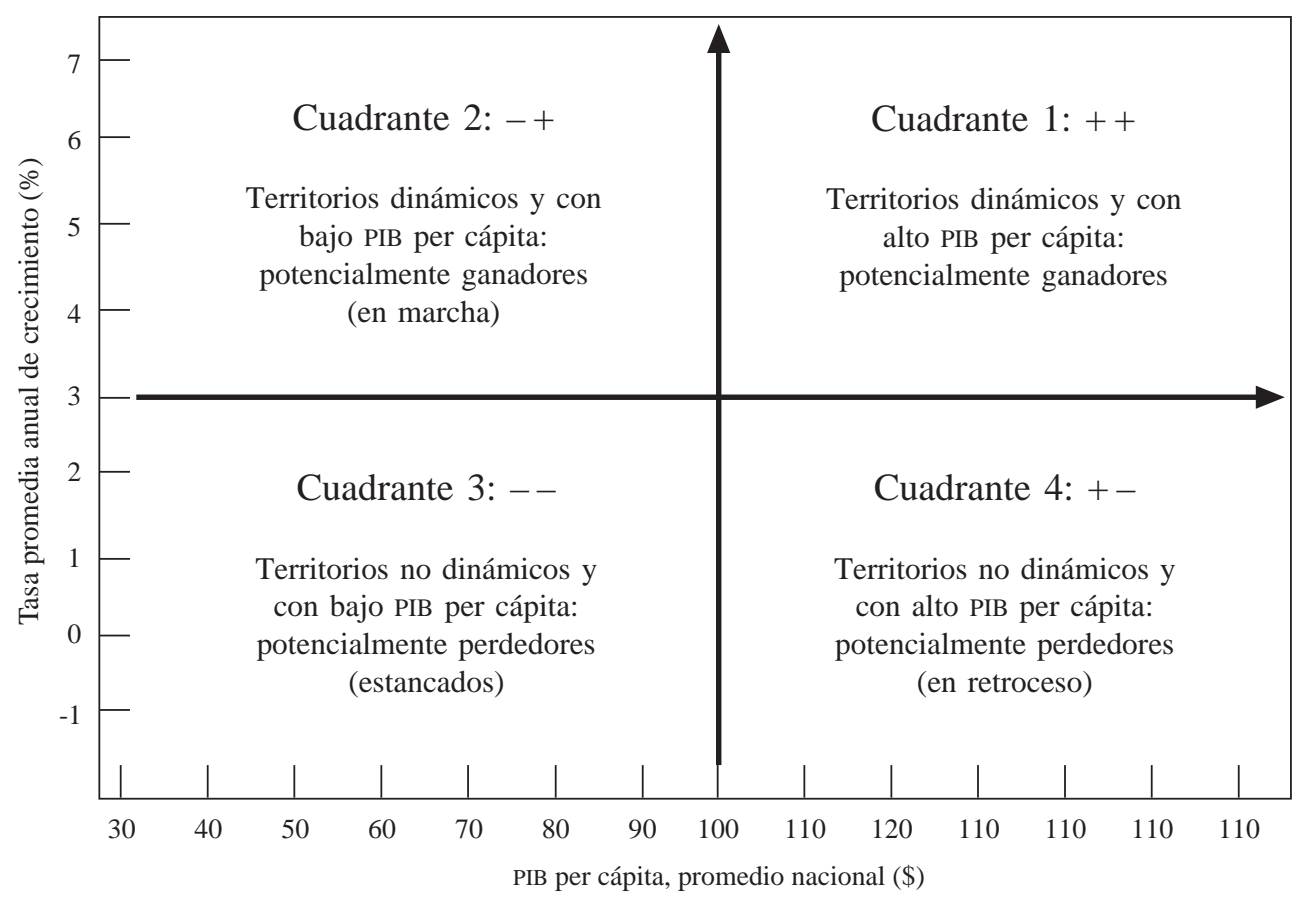

Fuente: Elaborado por el autor.

globalización, no hay pruebas de convergencia entre los territorios subnacionales.

Una situación similar se presenta en México, donde el modelo no arroja pruebas de que haya habido convergencia en el período 1993-1999. Tampoco hay indicios de convergencia para Bolivia en los períodos considerados ni para Perú en 1990-1995, situación que se reitera para Colombia tanto en la serie de 19801996 como en la de 1990-1996. En el caso de Brasil, cuando hay muestras de convergencia, el tiempo que tomaría reducir las brechas a la mitad va aumentando desde 35 años en el período 1970-1980 a 54 años en el período 1970-1997. Cuando se toma en forma aislada el período 1990-1997, a pesar de que el coeficiente no es significativo, no hay indicios de convergencia.

Se puede concluir que no hay muestras de convergencia territorial en los distintos países analizados y, por lo tanto, sería útil insistir en tener un diagnóstico más detallado de las características de las distintas economías subnacionales que pudieran explicar en alguna medida este comportamiento. Para ello, se propone construir una tipología de territorios, distinguiendo por ejemplo entre ricos y pobres, o ganadores y perdedores, para tratar de descubrir los atributos que hacen que algunos sean ganadores o las falencias que determinan que otros sean perdedores, con miras a identificar políticas explícitas que permitan a estos últimos converger hacia etapas de mayor crecimiento y desarrollo.

Sobre la base de la información disponible se generó el gráfico 4 . En este gráfico ${ }^{9}$ se produce el cruce

\footnotetext{
${ }^{9}$ La explicación más detallada de la construcción del gráfico 4 es la siguiente. La recta horizontal del eje de las abscisas $x$ corresponde a la tasa media de crecimiento del PIB a nivel nacional para el período considerado. De esta forma, los territorios subnacionales intermedios que se ubiquen por encima de este eje serán aquellos que hayan crecido por sobre el promedio nacional. En el ejemplo del gráfico 4 se plantea que la economía nacional creció, en un determinado período, al $3 \%$ como promedio anual. Por lo tanto, los territorios que se sitúen por arriba de este crecimiento medio serán considerados dinámicos y estarán en los cuadrantes 1 y 2 . La recta vertical del eje de las ordenadas $y$ corresponde al PIB per cápita medio a nivel nacional, de forma tal que los territorios que se ubiquen a la derecha de este eje tendrán un PIB per cápita superior al promedio nacional. En el ejemplo del mencionado gráfico, el PIB per cápita medio a nivel nacional es de 100 unidades monetarias, de modo que los territorios con promedios de PIB por encima de éste serán considerados como de alto PIB per cápita y corresponde-
} 


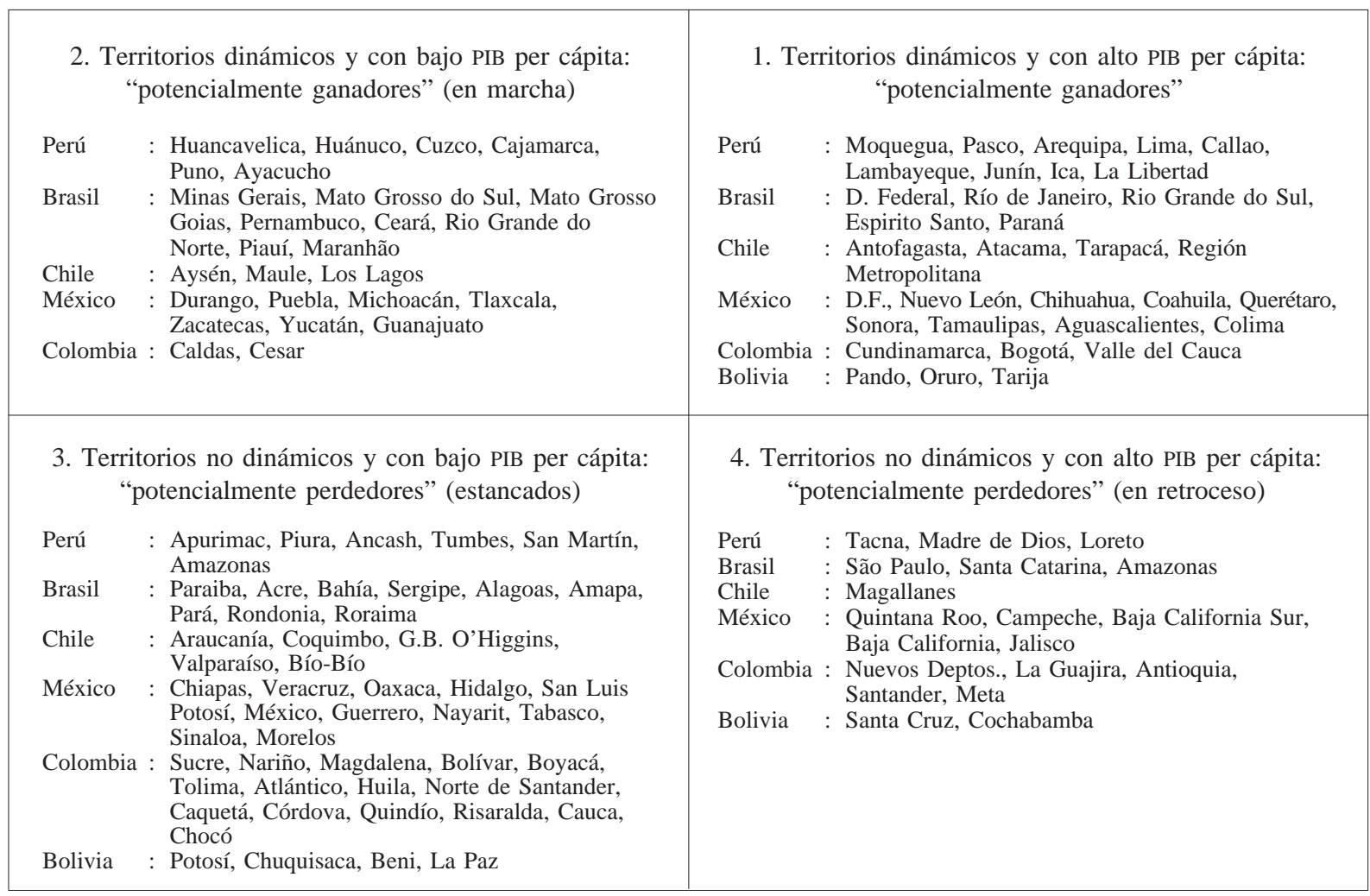

Fuente: Elaborado por el autor.

de los dos ejes cartesianos que determinan la configuración de cuatro cuadrantes, los que tienen diferentes dinámicas de crecimiento y permiten aventurar una interpretación de lo que está pasando en los distintos territorios de los países analizados. Los territorios concretos correspondientes a cada cuadrante se presentan en el cuadro $3 .{ }^{10}$

\section{Cuadrante 1: Territorios dinámicos y con alto PIB per cápita, "potencialmente ganadores"}

Agrupa los territorios que han crecido por sobre el promedio nacional y que tienen PIB per cápita también superiores a la media nacional y que, por lo tanto, se podrían considerar como los de comportamien-

rán a los cuadrantes 1 y 4 . Como se puede deducir, el cuadrante 3 es el de peor desempeño económico, ya que en él se hallan los territorios que han crecido por debajo del promedio nacional y que tienen PIB per cápita también inferiores al promedio nacional.

10 Véase un análisis más detallado de esta clasificación en Silva Lira (2003). to más exitoso frente a los procesos de globalización. ${ }^{11}$ Corresponden a zonas geográficas potencialmente ganadoras que acentúan o amplían su diferencia o brecha con los territorios de menor desarrollo relativo.

En este cuadrante se encuentran territorios en situaciones que podrían clasificarse así:

a) Territorios potencialmente ganadores con recursos naturales exportables: son territorios que aprovechan ventajas comparativas muy explícitas y marcadas, como las de la minería, lo que les ha

\footnotetext{
11 En realidad, esta clasificación persigue, en primera instancia, interpretaciones a lo que está pasando en los territorios subnacionales intermedios en los distintos países y, en tal sentido, este esquema de análisis probablemente planteará preguntas que obligarán a procesar otra información si se pretende dar una respuesta acertada. Se habla de territorios "potencialmente" ganadores, ya que, por la dinámica misma de los acontecimientos económicos, ser ganador hoy día no significa necesariamente serlo mañana; para seguir siéndolo se necesitan políticas y actitudes muy proactivas frente al proceso de internacionalización de la economía mundial.
} 
permitido atraer inversiones y proyectarse al mundo a través de sus exportaciones. La apertura al capital privado habría sido favorable a este tipo de territorios, que compiten básicamente a partir de una ventaja natural. Sin embargo, no pareciera que su tramado productivo y de servicios se haya densificado y diversificado lo suficiente como para que en ellos surjan efectivamente aglomeraciones productivas territoriales. En otras palabras, siendo hoy día territorios dinámicos, está por verse si serán capaces de construir ventajas competitivas avanzadas.

b) Territorios potencialmente ganadores que albergan áreas metropolitanas: en esta categoría se encuentran las zonas metropolitanas que a través del tiempo han concentrado normalmente mucha actividad económica y que se han transformado en centros financieros importantes y capitales de servicios. Son territorios con ciudades capitales o con grandes ciudades que han tenido un significativo proceso de terciarización de su economía y cuyo entorno urbano es la principal conexión del país con los mercados financieros internacionales.

Cuadrante 2: Territorios dinámicos y con bajo PIB per cápita, "potencialmente ganadores", en marcha

Incluye territorios que han crecido por sobre el promedio nacional y que tienen PIB per cápita inferiores a la media nacional. Podrían ser algo más pobres o atrasados que los demás (lo que se refleja en su PIB per cápita inferior), pero exhiben un buen ritmo de crecimiento y, en este sentido, se están aproximando a una situación más cercana a la convergencia con territorios más dinámicos, sobre todo si su mayor dinamismo relativo se sostiene.

En general, se trata de territorios que han iniciado interesantes procesos de crecimiento asociados a nuevas tecnologías y a ciertas reconversiones productivas más recientes, ${ }^{12}$ aprovechando ventajas comparativas que estaban latentes, como una base económica principalmente primario-exportadora o la posibilidad de agregar valor a sus procesos productivos a partir de recursos locales. Se les podría tipificar como territorios potencialmente ganadores que gracias a la globalización han sacado partido a recursos locales latentes.

\footnotetext{
12 Por ejemplo, las nuevas tecnologías de explotación minera que han revalorizado depósitos cuya explotación no era rentable anteriormente.
}

Cuadrante 3. Territorios no dinámicos y con bajo PIB per cápita, "potencialmente perdedores", estancados

Este cuadrante es exactamente el opuesto al cuadrante 1. En él se ubican territorios que han crecido por debajo del promedio nacional y cuyos PIB per cápita también son inferiores al promedio del país. Se los ha denominado "estancados", "potencialmente perdedores", ya que de mantenerse esta tendencia incrementarán su rezago, distanciándose aún más de los territorios de mayor progreso.

En este cuadrante se podría tipificar las siguientes situaciones:

a) Territorios potencialmente perdedores que se han desindustrializado y no han sido capaces de reconvertir cabalmente sus economías: se trata de territorios con estructuras industriales que fueron muy protegidas, cuya actividad económica ha venido en constante retroceso, que no han logrado reconvertir su aparato productivo y para los cuales la apertura y la globalización siguen siendo una amenaza. Sin embargo, coexisten entre ellos territorios locales que podrían constituir interesantes espacios de cambio e innovación.

b) Territorios potencialmente perdedores, con economías rurales de baja productividad y con escaso capital humano, que no se logran insertar en la economía global: son territorios agrícolas tradicionales que han estado normalmente rezagados, algunos de ellos con fuerte presencia de poblaciones indígenas; demandan una gran preocupación por parte del Estado central traducida en políticas compensatorias que atenúen su deterioro e identifiquen programas de recuperación específicos para cada situación concreta.

Cuadrante 4. Territorios no dinámicos y con alto PIB per cápita, "potencialmente perdedores", en retroceso

Aquí se incluyen aquellos territorios que han crecido por debajo de la media nacional y que tienen PIB per cápita superiores al promedio nacional. Se trata de territorios a los cuales en un pasado reciente les ha ido muy bien, ya que alcanzaron altos niveles de PIB per cápita, pero que han caído en períodos de contracción económica que pueden amagar su mejor situación relativa reciente; por ello se les considera en retroceso.

En este cuadrante se ubican, por lo tanto, los territorios que han perdido dinamismo por el agotamiento de ciertos recursos naturales o porque estos han perdido competitividad y/o mercados. Se podría decir que 
han sufrido una pérdida de ventajas comparativas, que puede ser permanente o pasajera, según sea la capacidad de reposicionamiento que tenga el ámbito local.
Estos territorios podrían ser tipificados como potencialmente perdedores que han retrocedido en sus capacidades competitivas. ${ }^{13}$

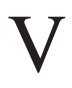

\section{Respuestas para el desarrollo local}

Vinculando lo planteado en las secciones anteriores y, en particular, el análisis de las disparidades y tipologías de los territorios, con la creación de territorios competitivos e innovadores, puede intentarse establecer qué tipo de políticas se debiera impulsar en función de las características de cada territorio particular. Además de lo ya enunciado, algunos de los antecedentes que es necesario tener en cuenta para hacerlo son los siguientes:

- No todos los territorios están igualmente preparados para enfrentar los procesos de apertura y globalización.

- Hay grandes disparidades territoriales que aconsejan distintos tipos de intervención en términos de políticas públicas locales.

- Las capacidades técnicas y de liderazgo de los gobiernos subnacionales (locales e intermedios) son desiguales.

- La lógica del desarrollo integral y, en particular, del apoyo a los procesos de desarrollo productivo no está plenamente incorporada en la agenda de los gobiernos subnacionales.

- La descentralización debe necesariamente acompañar los procesos de desarrollo subnacionales y es preciso hacer esfuerzos adicionales por descentralizar también los instrumentos de fomento productivo y desarrollo empresarial.

- Los planos mesoeconómico y microeconómico de la competitividad sistémica, si bien cobran mayor sentido en el ámbito territorial, deben ir acompañados y refrendados por políticas nacionales de fomento productivo e impulso a los procesos de innovación tecnológica. De lo contrario, los esfuerzos que se hagan a nivel subnacional pueden ser poco eficaces.

En definitiva, de lo que se trata es de determinar lo que se puede hacer desde el ámbito nacional y desde la endogeneidad de cada territorio para conseguir que las regiones atrasadas logren crecer más rápidamente, sin perjuicio de que los territorios más avanzados puedan mantener su buen comportamiento econó- mico. Como bien lo ha dicho Cuadrado Roura (2001) al referirse, en el contexto de estudios de convergencia regional en Europa, a los modelos macroeconómicos de crecimiento, "ellos siguen adoleciendo de un importante olvido. El factor espacio, el territorio, queda casi siempre al margen, cuando lo cierto es que bastantes de los factores cuya importancia se destaca porque explican o pueden explicar el mayor crecimiento de una economía, están localizados. Es decir que son factores que no son objetivamente trasladables a otro lugar; son poco móviles, o tienden a permanecer en un área determinada". Esto es lo que explica por qué si bien la escasez de capital en las regiones subnacionales más atrasadas debería hacer, de acuerdo con la teoría convencional, que estas fueran más atractivas para la inversión y el ahorro exterior, lo que en realidad ocurre

\footnotetext{
${ }^{13}$ Es muy probable que no haya una exacta correspondencia entre la clasificación establecida y el conocimiento "cultural" que se pueda tener de algunos de los territorios de los países presentados, en particular cuando se utilizan expresiones como "potencialmente ganadores o perdedores". A algunos incluso les podrá parecer que su territorio no quedó bien clasificado según su propia percepción. Aun cuando esta sensación se puede producir, lo que se busca es ver si es posible encontrar algunas tendencias o patrones de comportamiento que permitan identificar políticas públicas diferenciadas para cada territorio. Lo que sí es indudable es que si un territorio subnacional intermedio (región, departamento o estado) creció por debajo del promedio nacional y tiene un PIB per cápita también inferior a él, estamos hablando de un hecho totalmente objetivo, respecto del cual es poco lo que se puede hacer, al menos en términos de manipulación estadística. A modo de ejemplo, se podría citar el caso de Santa Cruz en Bolivia, que es conocido en general como uno de los departamentos más dinámicos y modernos del país. Sin embargo, aparece clasificado en el cuadrante 4 como territorio "potencialmente perdedor o en retroceso", porque pese a que su PIB per cápita es alto, tiene un crecimiento medio anual inferior al nacional. Lo que ocurre es que, en términos absolutos, la economía cruceña efectivamente ha mostrado un gran dinamismo, superior al del país, pero este dinamismo no ha alcanzado a compensar los grandes flujos migratorios recibidos: por eso, expresado en términos per cápita el crecimiento de su PIB se ubica por debajo del promedio nacional, al cual, paradójicamente, contribuye de manera importante. Esta es claramente una excepción a la regla de lo que puede ser el comportamiento más típico de los territorios que tienden a ubicarse en este cuadrante.
} 
suele ser lo contrario, porque la productividad de una inversión productiva o en capital físico puede ser baja si ella no va acompañada de inversiones en capital humano y tecnológico.

De aquí que en otra parte del documento citado, Cuadrado Roura (2001) agregue que "la existencia de esta serie de posibles ventajas y mejores dotaciones en un determinado territorio lo hacen no sólo más atractivo para recibir inversiones externas y más favorable para movilizar su propio potencial, sino que incorporan factores que implican la posibilidad de lograr unos rendimientos más altos. En último término, dichos factores hacen que el territorio en cuestión pueda ser más competitivo que otros y que, en consecuencia, también puedan serlo las empresas que desarrollen allí sus actividades productivas". Y, añadimos, hacen por lo tanto más factible la transformación competitiva de los sistemas productivos locales, en los términos en que se examinó anteriormente.

En la investigación indicada de Cuadrado Roura se analizan los factores que explican el mayor crecimiento de 16 territorios subnacionales de la Unión Europea. Entre los factores que al parecer fueron determinantes del mayor éxito económico de la UE, y que es importante tener en cuenta a la hora de tratar de identificar políticas públicas explícitas para incentivar el desarrollo de las zonas más atrasadas, se enumeran los siguientes:

i) Un sistema de ciudades medianas importantes y de poblaciones de tamaño mediano (40.000 a 150.000 habitantes), que parece constituir una clara ventaja para el crecimiento y la localización de las actividades, así como la disponibilidad de recursos humanos calificados y una base educativa media elevada. Si además los costos laborales relativos son moderados, el territorio cuenta con una ventaja adicional.

ii) La accesibilidad física del territorio; el acceso del territorio y sus agentes a los mercados internacionales; la posibilidad de acceso a quienes toman decisiones político-administrativas en el país; el acceso a las innovaciones y avances tecnológicos.

iii) La disponibilidad de servicios avanzados a la producción, como los de planificación estratégica, consultoría tecnológica, diseño, comercialización y exportación, investigación y desarrollo $(\mathrm{I}+\mathrm{D})$, y servicios financieros especializados.

iv) Una institucionalidad territorial avanzada: por ejemplo, un gobierno territorial con altas competencias y autonomía respecto de la administración central, un sistema de cooperación regular entre las distintas autoridades y con las organizaciones civiles (cámaras de comercio, organizaciones empresariales y sociales).

v) Clima social favorable, asociado a baja conflictividad laboral y cooperación entre las distintas instituciones públicas y privadas.

vi) Gran presencia de pequeñas y medianas empresas (pymes), reflejo de una base empresarial local apta para tomar nuevas iniciativas (Cuadrado Roura, 2001).

Los factores enumerados, si bien responden a la lógica europea, deben hacer reflexionar sobre el tipo de capacidades que es preciso desarrollar para tener posibilidades de éxito en un mundo cada vez más globalizado. Así, al menos, lo ha entendido Boisier, en su caso desde la perspectiva de un latinoamericano, ya que en innumerables artículos ha insistido en la necesidad de la mayor complejidad tecnológica e innovativa que deben desarrollar los territorios para que puedan responder a un mundo cada vez más complejo. En uno de esos artículos en particular afirma que "el nuevo escenario estratégico ${ }^{14}$ deriva de la intersección de dos procesos. Por un lado emerge una nueva geografía, más virtual que física, que genera nuevas modalidades de organización territorial, surgen nuevos tipos de regiones que derivan de una lógica sistémica y no del voluntarismo del tecnócrata. Transformados los territorios organizados en los nuevos actores de la competencia internacional por capital, por tecnología y por mercados, hay que maximizar las posibilidades de emerger como 'ganador' en la dura competencia globalizada. Examinadas empírica o especulativamente las características que exhiben las regiones ganadoras, varios autores apuntan aspectos tales como la complejidad sistémica, la velocidad decisional de las organizaciones, la capacidad innovativa, la flexibilidad, la

\footnotetext{
${ }^{14}$ Se refiere al nuevo escenario que deben enfrentar los territorios, en el cual se observan dos procesos de apertura, una externa y otra interna, que son a su vez resultado de procesos más complejos. La apertura externa, argumenta Boisier, es empujada por la globalización (que a su vez es acelerada y hecha posible por la revolución científica y tecnológica) en tanto que la apertura interna resulta de la descentralización funcional, territorial y política en marcha (una megatendencia catapultada a su vez por dicha revolución, por las demandas autonómicas de la sociedad civil, por la reforma del Estado y por la privatización); entre ambas formas de apertura, plantea que hay un mecanismo de interacción que es concluyente: no se puede ser competitivo ahora con estructuras de decisión centralizadas. Es decir, uno de los factores de éxito a los que se refería Cuadrado Roura, como es la presencia de gobiernos autonómicos y descentralizados, es aquí recalcada como una condición esencial para que los territorios puedan tener posibilidades de éxito.
} 
trama urbana, la infraestructura (pesada y liviana), la autonomía del gobierno respectivo, la cultura, etc. Muchas de estas características se asocian inversamente al tamaño y lo 'pequeño', hermoso o no, se revaloriza. Surge el concepto de región pivotal, como célula básica de una estructura piramidal en la que aparecen regiones asociativas, resultado de acuerdos entre territorios contiguos y, en último término, las más potentes y postmodernas, las regiones virtuales ya $\sin$ sometimiento a la restricción de la contigüidad espacial. En estos arreglos, el respeto a la voluntad democrática popular es irrestricto. Por otro lado, el escenario estratégico se asienta en nuevas formas de gestión territorial al dar cabida a la noción de región como cuasi-Estado y también como cuasi-empresa, usándose el primer concepto como un recordatorio del hecho de ser la cuestión del desarrollo regional una cuestión de naturaleza política expresada en relaciones de dominación y dependencia (de ahí la necesidad para toda región de acumular poder político) y el segundo concepto como indicación de la necesidad de imbuir a los gobiernos regionales de prácticas empresariales de gestión, en particular, la práctica de la gestión estratégica" (Boisier, 2000).

En resumen, a la luz de los trabajos recién comentados y que básicamente apuntan a la cuestión del carácter "ganador" o "perdedor" que tendrían determinados territorios, ya sea que el planteamiento se haga, en un caso, más en el plano conceptual y, en el otro, más en el plano empírico, es posible enumerar algunas de las condiciones que supuestamente convertirían a un territorio en "ganador". Por lo general, ellas se refieren a la infraestructura pesada (vinculada a transportes y comunicaciones) y a la infraestructura liviana (asociada a los servicios a la producción), así como a las condiciones estructurales del sistema territorial en cuestión.

Desde otro punto de vista, también se especula acerca de las condiciones que deben tener las organizaciones del tejido productivo e institucional de los territorios "ganadores" y desde tal perspectiva se apunta a la "velocidad" organizacional para tomar decisiones, a la "flexibilidad" de las propias estructuras para dotarlas de alta capacidad de adaptación al medio, a la "complejidad" sistémica de las organizaciones territoriales para equipararlas a la complejidad del "juego globalizador", a la "resiliencia" o capacidad de reconstitución del tejido dañado por elementos exógenos y, finalmente, a la "cultura" territorial, productora de identidad y de particularismos que pueden transformarse en nichos comerciales.

En definitiva, si uno se queda con esta imagen, en alguna medida sofisticada, de todas las condicio- nes que deberían cumplir los territorios que aspiran a ser ganadores, aunque tales condiciones sean efectivamente ciertas y necesarias, surge la sensación de que, al amparo de la gran heterogeneidad territorial prevaleciente, para muchos territorios sería difícil acceder a estadios superiores de desarrollo. Más bien queda la impresión de que la mayoría de los territorios de América Latina estarían lejos de poder desarrollar las capacidades señaladas y, por lo tanto, de insertarse con posibilidades de éxito en la economía internacional.

Conscientes de esta dificultad, creemos que, teniendo como marco de referencia los desafíos que aquí se han planteado, lo crucial es saber reconocer el punto de partida de cada territorio específico - por ejemplo, las tipologías que se enumeraban en la sección anterior-y luego ser capaces de identificar políticas públicas diferenciadas para cada uno de ellos. No se trata, por lo tanto, de utilizar las condiciones enumeradas como una suerte de lista de verificación para comprobar si cada territorio ha podido cumplir con todas las exigencias, sino que más bien de ver cómo se puede encaminar la elaboración social de distintas respuestas que, yendo en la dirección de la competitividad territorial, la innovación, el cambio tecnológico, la complejidad, etc., sean propias de las necesidades y posibilidades de cada territorio particular.

En función de lo que se argumentaba anteriormente, esa lista de verificación debe ser solamente un recordatorio de algunas de las características que pueden tener o haber tenido algunos "territorios ganadores", entre las cuales quizás la más importante sea la de desarrollar la capacidad de aprovechar con eficiencia los recursos locales endógenos, propiciando la asociatividad y la articulación público-social-privada con miras a flexibilizar los procesos productivos, en el contexto de procesos de gestión estratégicos territoriales que apuntan a las transformación de los sistemas productivos locales.

En el gráfico 5 se busca ilustrar el sentido que podría tener la diferenciación de políticas en función de las tipologías de territorios y de los factores de éxito de los llamados "territorios ganadores".

En el gráfico 5 se han agrupado en distintos niveles las condiciones que, según se estima, deben tener los territorios ganadores, y esos niveles de condiciones se han asociado a los distintos tipos de territorios. La interpretación que se puede dar a dicho gráfico es la siguiente:

i) Territorios estancados (- -): En este caso, las líneas punteadas pretenden identificar acciones de los niveles 1 y 4 . Es decir, en estos territorios, dadas sus 


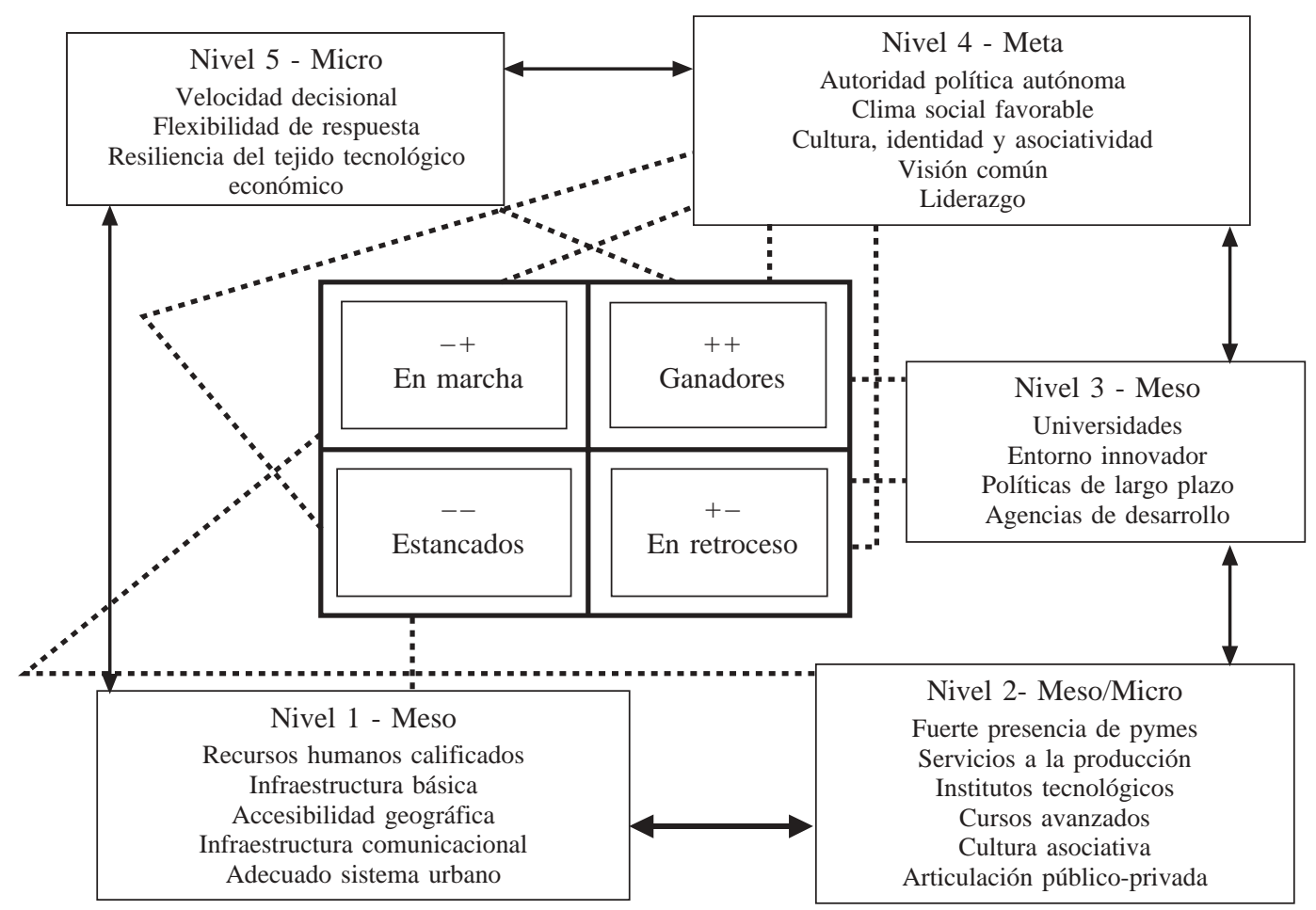

Fuente: Elaborado por el autor.

características, hay que hacer mayor hincapié en la identificación de políticas dirigidas a la calificación de recursos humanos — probablemente al incremento de los años de escolaridad de la población-y al desarrollo de infraestructura básica y otros aspectos que tienen que ver principalmente con la falta de inversión en infraestructura tangible que puede estar obstaculizando el avance de estos territorios (condiciones de nivel 1). El nivel 4, que es común a todos los territorios, debiera ser importante para todos ellos, ya que se relaciona principalmente con condiciones institucionales e intangibles que suelen no requerir recursos financieros, como una autoridad política autónoma, un clima social favorable, una cultura territorial, una visión común de desarrollo.

ii) Territorios ganadores $(++)$ : En este otro extremo, por tratarse de territorios ganadores que se supone ya cumplen con muchas de las condiciones enumeradas, se insiste más en dar impulso a condiciones clasificadas en los niveles 3 y 5 , es decir, la existencia de universidades comprometidas con el desarrollo del territorio, que aporten a la investigación científica y tec- nológica asociada al tejido productivo regional; formar e impulsar entornos innovadores, y crear capacidades que propicien tomas de decisiones más rápidas y mayor flexibilidad de respuesta ante un mundo cambiante. Es decir, lo que se busca es hacer mayor hincapié en condiciones bastante más sofisticadas, suponiendo que existe una masa crítica capaz de impulsarlas.

iii) Territorios en marcha (-+): En este caso, como se trata de territorios que están evolucionando positivamente pero en los cuales todavía persisten condiciones sociales y económicas atrasadas, se insiste más en impulsar acciones encaminadas a desarrollar servicios de apoyo a la producción y promover institutos tecnológicos y cursos avanzados para capacitar y actualizar recursos humanos, características todas que dicen relación con un activo aparato de producción que demanda apoyos efectivos para consolidarse.

iv) Territorios en retroceso (+-): Como se trata de territorios que tuvieron una evolución económica y social bastante buena en el pasado reciente, se hace mayor hincapié en aspectos relacionados con el desarrollo de la capacidad de innovación para recuperar las 
sendas de crecimiento y desarrollo perdidas. En estos territorios, donde probablemente muchos de los esfuerzos en materia de infraestructura, accesibilidad, sistema urbano y otros similares ya han tenido resultados satisfactorios, los mayores desafíos pueden estar asociados a ciertas reconversiones que sería necesario fomentar para reinsertarse con éxito en la economía global.

Aunque los factores enumerados contribuyan efectivamente a alcanzar posiciones "ganadoras", no se debe desestimar el significado mismo de los procesos de desarrollo y las formas que ellos pueden adoptar. En este sentido, cobra cada día más vigencia lo que, ya en la década de 1980, señalaba Celso Furtado:

\section{Haré una reflexión final, derivada de mi contac-} to en éste y en otros países, con los problemas de regiones que acumularon un gran atraso económico. Durante mucho tiempo prevaleció en todas partes la tendencia a imaginar que el desarrollo es algo cuantificable, cuyo sustrato es la acumulación, la inversión, la formación de capacidad productiva. Sin embargo, la experiencia ha demostrado ampliamente que el verdadero desarrollo es principalmente un proceso de activación y canalización de fuerzas sociales, de mejoría de la capacidad asociativa, de ejercicio de la iniciativa y de la inventiva. Por lo tanto, se trata de un proceso social y cultural, y sólo secundariamente económico. El desarrollo se produce cuando en la sociedad se manifiesta una energía capaz de canalizar, de forma convergente, fuerzas que estaban latentes o dispersas.

Una verdadera política de desarrollo tendrá que ser la expresión de las preocupaciones y aspiraciones de grupos sociales que toman conciencia de sus problemas y se empeñan en resolverlos. No obstante, sólo la actividad política puede canalizar esas energías de forma de producir los fenómenos de sinergia a que hice referencia. Qué otra cosa sino la rarefacción de la vida política explica que, entre nosotros, los problemas del desarrollo hayan pasado a ser encarados como simples cuestiones técnicas, prevaleciendo una visión simplificada de los procesos sociales y culturales (Furtado, 1982, traducción del autor).

Las palabras de Furtado se aplican bien al desarrollo territorial, ya que es en la vecindad de las relaciones que se establecen en el plano territorial donde resulta más factible "canalizar, de forma convergente, fuerzas que estaban latentes o dispersas". Esto, en gran medida, se puede ver como la tarea de aglutinar tras una visión común, con el liderazgo que sea necesario imprimir desde lo local, a agentes públicos y privados que, cohesionados bajo una cultura territorial que los hace propios y distintos, son capaces de emprender proyectos de desarrollo innovadores, para lo cual se apoyan en el potencial de recursos endógenos con que cuenta el territorio. Es decir, y sin perjuicio de tener como telón de fondo la lista que nos recuerda las características de los llamados territorios "ganadores", de lo que se trata es de desarrollar ciertos capitales sinérgicos, normalmente asociados a capitales intangibles, que permitan efectuar una "canalización convergente de fuerzas dispersas" para, con la misma dotación de recursos ya disponibles, avanzar más rápido y mejor en pos de lo objetivos propuestos. ${ }^{15}$

Este es un desafío que está pendiente y para el cual muchos de los territorios subnacionales de América Latina pueden estar preparados por contar con potencialidades ciertas, como identidades locales muy afianzadas; comunidades con culturas de cooperación bastante desarrolladas; procesos de descentralización en marcha en diversas etapas de desarrollo; gobiernos locales cada vez más conscientes de la necesidad de liderar y articular procesos de desarrollo local; fuerte presencia de pymes con una distribución territorial relativamente homogénea, y capacidades empresariales a las que se puede dar mayor impulso.

En definitiva, al elaborar respuestas para fomentar el desarrollo subnacional y construir territorios competitivos e innovadores, si bien se parte de realidades muy

\footnotetext{
15 Boisier (2000) hace una detallada descripción de los capitales intangibles en los procesos de desarrollo. En una parte de este trabajo dice: "En cualquier caso, siendo el desarrollo un resultado intangible, habrá que identificar su causalidad en esa misma dimensionalidad. Es decir, ahora se trata de identificar, en el lugar y en el tiempo, cuáles son los factores intangibles que están detrás del desarrollo. Como esos factores son muy variados, pero agrupables en categorías relativamente homogéneas, no resulta inapropiado introducir el concepto de capital intangible, para referirse a grupos de factores intangibles. Lo que sigue es un listado de capitales intangibles que pueden, eventualmente, estar presentes en cualquier región”. Y más adelante enumera los siguientes capitales intangibles: capital cognitivo, simbólico, cultural, social, cívico, institucional, psicosocial y humano, para agregar en otra parte que: "El hecho de encontrarse los capitales intangibles más fácilmente en territorios de pequeña escala no hace sino reafirmar la idea de que el desarrollo siempre ha sido y siempre será un fenómeno que en sus inicios es de pequeña escala, local, descentralizado y ciertamente endógeno. Esta afirmación es de la mayor importancia teórica y práctica, ya que desde este último punto de vista revaloriza la escala comunal y quizás si principalmente la escala provincial, a lo menos en Chile".
} 
diversas por las enormes desigualdades territoriales prevalecientes, es posible apoyarse en algunos aspectos comunes y característicos:

i) Primero, se trata de procesos de naturaleza endógena, en los cuales es preciso estimular la capacidad de detectar las potencialidades propias -naturales, humanas, institucionales y organizacionales- presentes en el territorio, con el fin de saber para qué "somos buenos". En otras palabras, algo habrá para lo que estemos mejor dotados y capacitados y que pueda inspirar nuestras visiones de futuro.

ii) Las estrategias que se formulen tienen que estar basadas en el concepto de solidaridad territorial mediante la afirmación de la identidad cultural. Esto significa, en definitiva, construir socialmente un proyecto político territorial que identifique a toda la comunidad y que logre transformarse en una visión común de desarrollo y que, al tener su sello propio, llegue a constituirse en lo que nos diferencia de los demás.

iii) La estrategia debe estar basada en una gestión asociativa entre representantes públicos y privados: esto implica estar convencidos de que solos no saldremos adelante y que, por lo tanto, hay que impulsar proyectos que conciten consenso y que, además, sean de largo plazo y trasciendan la esfera de un determinado gobierno.

Indudablemente, el desafío de impulsar procesos de desarrollo subnacional en América Latina demanda esfuerzos enormes, algunos de los cuales están vinculados con aspectos institucionales, organizativos, de coordinación, de articulación, etc., que no siempre exigen recursos financieros, aunque por cierto ellos son necesarios. De ser así, esto significa que hay espacios para proyectos políticos innovadores que apunten a la construcción de territorios competitivos y, por lo tanto, a la transformación de los sistemas productivos locales.

APÉNDICE

América Latina (seis países): Análisis de convergencia y divergencia subnacionales (beta)

\begin{tabular}{|c|c|c|c|c|c|c|}
\hline \multirow[t]{2}{*}{ Período } & \multicolumn{5}{|c|}{ Resultados de la regresión no lineal } & \multirow[b]{2}{*}{$\begin{array}{l}\text { Tiempo para reduci } \\
\text { la brecha a la mitad }\end{array}$} \\
\hline & $\begin{array}{c}\text { Coeficiente } \\
\beta 1\end{array}$ & $\begin{array}{l}\text { Error estándar } \\
\quad(\beta 1)\end{array}$ & $\mathrm{T}$ & $\begin{array}{l}\text { Significación } \\
\text { del coeficiente }\end{array}$ & $\mathrm{R}^{2}$ & \\
\hline \multicolumn{7}{|l|}{ Perú } \\
\hline $\begin{array}{l}1970-1980 \\
1980-1990 \\
1990-1995 \\
1970-1995\end{array}$ & $\begin{array}{l}0,011 \\
0,014 \\
0,009 \\
0,010\end{array}$ & $\begin{array}{l}0,013 \\
0,006 \\
0,011 \\
0,006\end{array}$ & $\begin{array}{l}0,858 \\
2,382 \\
0,852 \\
1,768\end{array}$ & $\begin{array}{l}\text { No } \\
\text { Al } 5 \% \\
\text { No } \\
\text { No }\end{array}$ & $\begin{array}{l}0,038 \\
0,237 \\
0,035 \\
0,160\end{array}$ & $\begin{array}{l}\text { No convergen } \\
51 \text { años } \\
\text { No convergen } \\
\text { No convergen }\end{array}$ \\
\hline \multicolumn{7}{|l|}{ Brasil } \\
\hline $\begin{array}{l}1970-1980 \\
1980-1990 \\
1990-1997 \\
1970-1997\end{array}$ & $\begin{array}{l}0,020 \\
0,014 \\
0,011 \\
0,013\end{array}$ & $\begin{array}{l}0,010 \\
0,006 \\
0,012 \\
0,005\end{array}$ & $\begin{array}{l}2,063 \\
2,250 \\
0,866 \\
2,698\end{array}$ & $\begin{array}{c}\text { Al } 10 \% \\
\text { Al 5\% } \\
\text { No } \\
\text { Al } 5 \%\end{array}$ & $\begin{array}{l}0,185 \\
0,196 \\
0,033 \\
0,311\end{array}$ & $\begin{array}{l}35 \text { años } \\
48 \text { años } \\
\text { No convergen } \\
54 \text { años }\end{array}$ \\
\hline \multicolumn{7}{|l|}{ Chile } \\
\hline $\begin{array}{l}1970-1980 \\
1980-1990 \\
1990-1998 \\
1970-1998\end{array}$ & $\begin{array}{l}0,006 \\
0,013 \\
0,004 \\
0,011\end{array}$ & $\begin{array}{l}0.005 \\
0,004 \\
0,013 \\
0,005\end{array}$ & $\begin{array}{l}1,235 \\
3,203 \\
0,320 \\
2,232\end{array}$ & $\begin{array}{l}\text { No } \\
\text { Al 5\% } \\
\text { No } \\
\text { Al } 5 \%\end{array}$ & $\begin{array}{l}0,129 \\
0,516 \\
0,010 \\
0,414\end{array}$ & $\begin{array}{l}\text { No convergen } \\
53 \text { años } \\
\text { No convergen } \\
61 \text { años }\end{array}$ \\
\hline \multicolumn{7}{|l|}{ México } \\
\hline 1993-1999 & 0,002 & 0,006 & 0,318 & No & 0,00339 & No convergen \\
\hline \multicolumn{7}{|l|}{ Colombia } \\
\hline $\begin{array}{l}1980-1996 \\
1990-1996\end{array}$ & $\begin{array}{l}-0,006 \\
-0,017\end{array}$ & $\begin{array}{l}0,008 \\
0,013\end{array}$ & $\begin{array}{l}-0,814 \\
-1,308\end{array}$ & $\begin{array}{l}\text { No } \\
\text { No }\end{array}$ & $\begin{array}{l}0,025 \\
0,063\end{array}$ & $\begin{array}{l}\text { No convergen } \\
\text { No convergen }\end{array}$ \\
\hline \multicolumn{7}{|l|}{ Bolivia } \\
\hline $\begin{array}{l}1990-1998 \\
1988-1998\end{array}$ & $\begin{array}{r}-0,019 \\
0,002\end{array}$ & $\begin{array}{l}0,026 \\
0,032\end{array}$ & $\begin{array}{r}-0,727 \\
0,046\end{array}$ & $\begin{array}{l}\text { No } \\
\text { No }\end{array}$ & $\begin{array}{l}0,061 \\
0,000\end{array}$ & $\begin{array}{l}\text { No convergen } \\
\text { No convergen }\end{array}$ \\
\hline
\end{tabular}

Fuente: Elaborado por el autor. 


\section{Bibliografía}

Altenburg, T., W. Hillebrand y J. Meyer-Stamer (1988): Building Systemic Competitiveness: Concept and Case Studies from Mexico, Brazil, Paraguay, Korea and Thailand, Berlín, Instituto Alemán de Desarrollo.

Barro, R. y X. Sala-i-Martin (1991): Convergence across states and regions, Brookings Papers on Economic Activity, $\mathrm{N}^{\circ}$ 1, Washington, D.C., The Brookings Institution.

(1992a): Convergence, Journal of Political Economy, vol. 100, $\mathrm{N}^{\mathrm{o}}$ 2, Chicago, The University of Chicago Press.

(1992b): Regional growth and migration: a Japan-United States comparison, Journal of the Japanese and International Economies, vol. 6, № 4, Amsterdam, Elsevier Science, diciembre.

Bianchi, P. y M. Parrillo (2002): Obstáculos y oportunidades de inversión para el desarrollo de las pequeñas y medianas empresas en Chile, Bolonia, Italia, Universidad de Ferrara, y Nomisma consultores.

Boisier, S. (1996): Modernidad y territorio, serie Cuadernos del ILPES, $\mathrm{N}^{\circ}$ 42, LC/IP/G.90-P, Santiago de Chile, Instituto Latinoamericano y del Caribe de Planificación Económica y Social (ILPES). Publicación de las Naciones Unidas, $\mathrm{N}^{\mathrm{o}}$ de venta: S.96.III.F.1.

(2000): Conversaciones sociales y desarrollo regional: potenciación del capital sinergético y creación de sinergia cognitiva en una región, Talca, Universidad de Talca.

Buitelaar, R. (2001a): Cómo crear competitividad colectiva, La estrategia económica del Tolima, Tolima, Centro de Productividad del Tolima/Fondo Colombiano de Investigaciones Científicas y Proyectos Especiales (Colciencias).

(comp.) (2001b): Aglomeraciones mineras y desarrollo local en América Latina, Bogotá, D.C., CEPAL/Alfaomega.
Cabrera, A., S. de la Cuadra y otros (2002): Las pyme: quiénes son, cómo son y qué hacer con ellas, Santiago de Chile, Sociedad de Fomento Fabril (SOFOFA).

Cuadrado Roura, J.R. (2001): Convergencia regional en la Unión Europea. De las hipótesis teóricas a las tendencias reales, en T. Mancha Navarro y D. Sotelsek Salem (comps.), Convergencia económica e integración. La experiencia en Europa y en América Latina, Madrid, Ediciones Pirámide.

Furtado, C. (1982): A nova dependencia, Río de Janeiro, Editora Paz e Terra.

Mancha Navarro, T. y D. Sotelsek Salem (comps.) (2001): Convergencia económica e integración. La experiencia en Europa y América Latina, Madrid, Ediciones Pirámide.

Mankiw, N. G., D. Romer y N. Weil (1992): A contribution to the empirics of economic growth, Quarterly Journal of Economics, vol. 107, No 2, Cambridge, Massachusetts, The MIT Press.

Meyer-Stamer, J. (2000): Estrategias de desarrollo local y regional: clusters, política de localización y competitividad sistémica, El mercado de valores, vol. 60, N 9, México, D.F., Nacional Financiera, septiembre.

Porter, M. (1991): La ventaja competitiva de las naciones, Buenos Aires, Javier Vergara Editor.

Sala-i-Martin, X. (1990): On Growth and States, tesis, Harvard, Universidad de Harvard.

(2000): Apuntes de crecimiento económico, Barcelona, Antoni Bosch editor.

Silva Lira, I. (2003): Disparidades, competitividad territorial y desarrollo local y regional en América Latina, serie Gestión pública, No 33, LC/L.1882-P, Santiago de Chile, Comisión Económica para América Latina y el Caribe (CEPAL), abril. Publicación de las Naciones Unidas, $\mathrm{N}^{\mathrm{o}}$ de venta: S.03.II.G.47. 